\title{
Combined effects of combustion chamber geometry and injection strategy on combustion and emissions of a diesel engine
}

\author{
Jizhou Zhang ${ }^{1,2,3}$, Fuwu Yan $^{1,2}$, and Yu Wang 1,2,3,* \\ ${ }^{1}$ Hubei Key Laboratory of Advanced Technology for Automotive Components, Wuhan University of \\ Technology, Wuhan 430070, China \\ ${ }^{2}$ Hubei Collaborative Innovation Center for Automotive Components Technology, Wuhan University \\ of Technology, Wuhan 430070, China \\ ${ }^{3}$ Laboratory for Advanced Combustion, School of Automotive Engineering, Wuhan University of \\ Technology, Wuhan 430070, China
}

Keywords: combustion chamber geometry, injection strategy, combustion, emissions, CFD simulation, diesel engine.

\begin{abstract}
For a certain type of direct injection diesel engine, a threedimensional model of a single-cylinder complete combustion chamber and in-take/exhaust port was established. Three-dimensional Computational Fluid Dynamics (CFD) analysis software CONVERGE was used for simulation. The effects of fuel injection strategy and combustion chamber geometry on combustion emissions of diesel engine were studied while the combustion chamber volume, engine compression ratio, total fuel injection quantity and total injection duration were kept unchanged. The results show that the strategy of multiple injection and reasonable shape of combustion chamber can effectively increase the turbulent kinetic energy in cylinder, improve the uniformity of oil-gas mixing, reduce the emission of pollutants, and increase the quality of after injection can further reduce the emissions of NOx and soot.
\end{abstract}

\section{Introduction}

Compared with gasoline engine, diesel engine has good fuel economy, reliability and higher thermal efficiency, so it is widely used in agriculture, industry, transportation and other fields. However, diesel Engine also has disadvantages of increased emission from diesel and nitrogen oxides(NOX).

The shape of the diesel engine combustion chamber and fuel injection strategy directly affect the process of mixing, burning and emission of oil and gas.

Husberg ${ }^{[1]}$ studied the impact of diesel pre-injection and multiple injection strategies on heavy direct injection diesel engine emissions. The author finds that pre-injection can increase soot oxidation time, thus reducing $\mathrm{NO}_{\mathrm{X}}$ and soot emission, but carbon emission $(\mathrm{CO})$ will increase.

\footnotetext{
* Corresponding author: yu.wang@whut.edu.cn
} 
Mobasheri ${ }^{[2]}$ studied the effects of pre-injection, post-injection, multiple main jets, different fuel injection intervals and different fuel injection volume ratios on the performance and emissions of heavy direct injection diesel engine. The author found that multiple fuel injection and the injection interval and single injection quantity optimization can effectively improve the mix of oil and gas, the mixture in cylinder is more thin, thus effectively reducing $\mathrm{NO}_{\mathrm{X}}$ and soot emissions.

Puri lng ${ }^{[3]}$ studied the comprehensive effects of fuel injection starting time, fuel injection duration and fuel injection pressure on the combustion and emission of direct injection diesel engine. It is found that, limit $\mathrm{NO}_{\mathrm{X}}$, soot and $\mathrm{HC}$ emission by delaying the start time of injection and increasing injection pressure, but $\mathrm{CO}$ emission can be increased.

Zhang Yanhui ${ }^{[4]}$ studied the impact of key combustor features on economy and emissions, and designed an optimization scheme for combustor.

R. Dakhore ${ }^{[5]}$ studied the influence of the crater shape of the combustion chamber on the performance, combustion and emission of the medium-sized direct-injected diesel engine. The author compares the simulation results of four kinds of combustor shapes, and finds that increasing swirl chamber pit shape can improve oil and gas mixing and combustion, and thus reduce $\mathrm{NO}_{\mathrm{X}}$ and soot emission.

$\mathrm{X} . \mathrm{Li}^{[6]}$ studied the influence of a series of lateral combustor on the combustion and emission of direct jet diesel engine. The author compares the simulation results of this combustion chamber under different geometric parameters, and finds that matching this combustion chamber with appropriate geometric parameters can reduce $\mathrm{NO}_{\mathrm{X}}$ and soot emission effectively. On the basis of previous researches, this paper adopts numerical simulation method to study the comprehensive influence of fuel injection strategy and combustion chamber shape on diesel engine emission.

Using a three-dimensional computational fluid dynamics (CFD) analysis software CONVERGE on three different injection strategies and four different combustion chamber geometry scheme has carried on the simulation analysis. The combined influence of fuel injection strategy and combustion chamber shape is analyzed comprehensively, which provides certain theoretical basis and research contribution for improving diesel engine combustion efficiency and reducing pollutant emission.

\section{Fundamentals of numerical simulation}

This article focuses on a direct jet diesel engine. The basic parameters of diesel engine are shown in Table 1. The diesel engine geometric model is shown in Figure 1(a), (b), and (c).

Table 1. Diesel engine basic parameter table.

\begin{tabular}{cc}
\hline Parameter & Value \\
\hline The cylinder diameter & $105 \mathrm{~mm}$ \\
Length of stroke & $125 \mathrm{~mm}$ \\
Compression ratio & 17.5 \\
The number of the nozzle & 7 \\
The nozzle diameter & $0.149 \mathrm{~mm}$ \\
Rotation rate & $2200 \mathrm{r} / \mathrm{min}$ \\
\hline
\end{tabular}

It adopts the CONVERGE of 3D CFD analysis software to conduct simulation. A variety of physical, chemical and combustion models are used in the simulation process.

The spray model uses the discrete droplet model to simulate the fuel injection process. The mixed KH-RT model was used to simulate the atomization and crushing process of the spray ${ }^{[7,8]}$, and the discrete multi-component vaporization model was used to simulate the vaporization process ${ }^{[9]}$. 
The turbulence model uses the RNG k- $\varepsilon$ model.

Combustion models use CONVERGE's own SAGE model to simulate the combustion process. The model contains the control equations of conservation of mass and conservation of energy, which can be solved in each time step for a given computing unit.

The reaction mechanism of N-butanol-diesel oil combustion was developed by Wang ${ }^{[10]}$. The mechanism contains 76 substances and 349 reactions, which can comprehensively and accurately simulate the reaction of the actual combustion process.

The pollutant generation process of emissions is constructed by using Extended Zeldovich $\mathrm{NO}_{\mathrm{X}}$ model and Hiroyasu soot model. The specific numerical model selection is shown in Table 2.

Table 2. Simulation numerical model selection.

\begin{tabular}{cc}
\hline Model & Intall \\
\hline Turbulence model & RNG k- $\varepsilon$ model \\
Atomization and crushing model of spray & KH-RT model \\
Collision model & NTC Collision model \\
Combustion model & SAGE model \\
NOX model & Extended Zeldovich model \\
Soot model & Hiroyasu soot model \\
\hline
\end{tabular}

In this paper, the simulation starts from the intake valve opening moment (370 degrees before top stop point) and ends at the exhaust valve opening moment (130 degrees after top stop point).

The cartesian grid of simulation models with a base size of $4 \mathrm{~mm}$ utilizes adaptive mesh (AMR) function in CONVERGE. This function can adjust the size of grid adaptively according to key factors such as temperature, speed and substance concentration.

At the same time, this paper sets mesh encryption for key parts such as cylinder and fuel injection nozzle, and the highest encryption level is level 3. The surface mesh and encryption are shown in Figure 1 (d).

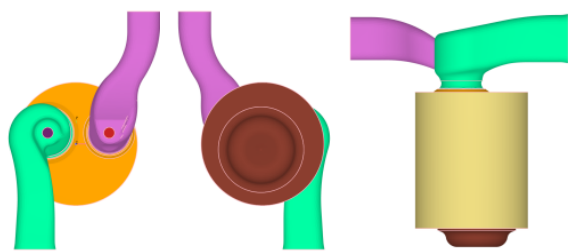

(a) Top view (b) Elevation view (c) Side view

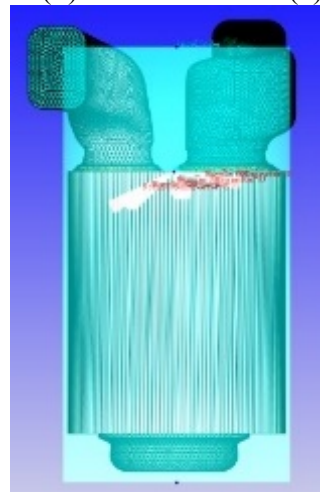

(d) Surface mesh and encryption

Fig. 1. Diesel engine geometric model, surface mesh and encryption. 


\section{Model validation}

In order to verify the accuracy of the simulation model, this paper conducts simulation calculation with the fuel injection strategy of the original machine, which is shown in Table 3.

The test results of the original machine were compared with the simulation results, and the test and simulation results were compared as shown in Table 4.

By comparing the test and simulation results in Table 3, it can be found that the peak cylinder pressure, peak temperature, power and torque of the two have a small difference, and the error is within 3\%. Therefore, it can be considered that the mathematical model and boundary conditions selected by the simulation calculation are accurate and the simulation model is reliable.

Table 3. Original fuel injection strategy.

\begin{tabular}{|c|c|c|c|c|}
\hline Plan & Parameter & Pre-spraying & Interval & Main spraying \\
\hline \multirow{2}{*}{$\begin{array}{l}\text { Original } \\
\text { machine }\end{array}$} & $\begin{array}{c}\text { Fuel injection } \\
\text { quantity/mg }\end{array}$ & 2 & - & 68.7 \\
\hline & Crank Angle/( ATDC) & -24.9 to -21.6 & 14 & -7.6 to -5.1 \\
\hline
\end{tabular}

Table 4. Comparison of experimental and simulation results.

\begin{tabular}{ccccc}
\hline Plan & Peak cylinder pressure/MPa & $\begin{array}{c}\text { Peak } \\
\text { temperature/K }\end{array}$ & Power/kW & Torque/(N·m) \\
\hline Experiment & 15.99 & 1640.31 & 129.21 & 560.8 \\
Simulation & 16.38 & 1644.62 & 128.18 & 556.42 \\
\hline
\end{tabular}

\section{Simulation plan setting}

In this paper, the comprehensive effects of three combustion chamber shapes and four fuel injection strategies on diesel engine combustion and emission are studied. The fuel injection strategy scheme in this paper is shown in Table 5, where the total amount of fuel injection, the total duration of fuel injection and the initial time of fuel injection all remain unchanged.

The 2D contour of the combustor scheme is shown in Figure 2, and the 3D schematic diagram is shown in Figure 3. The combustor geometry is changed, but the combustor volume and engine compression ratio are kept unchanged.

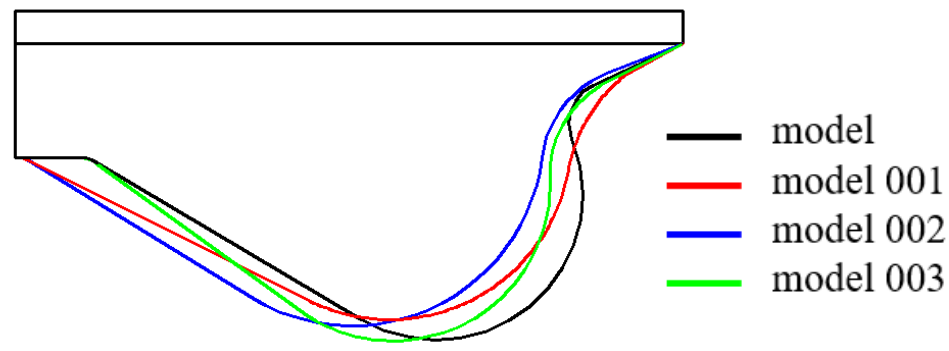

Fig. 2. 2D diagram of combustion chamber scheme. 


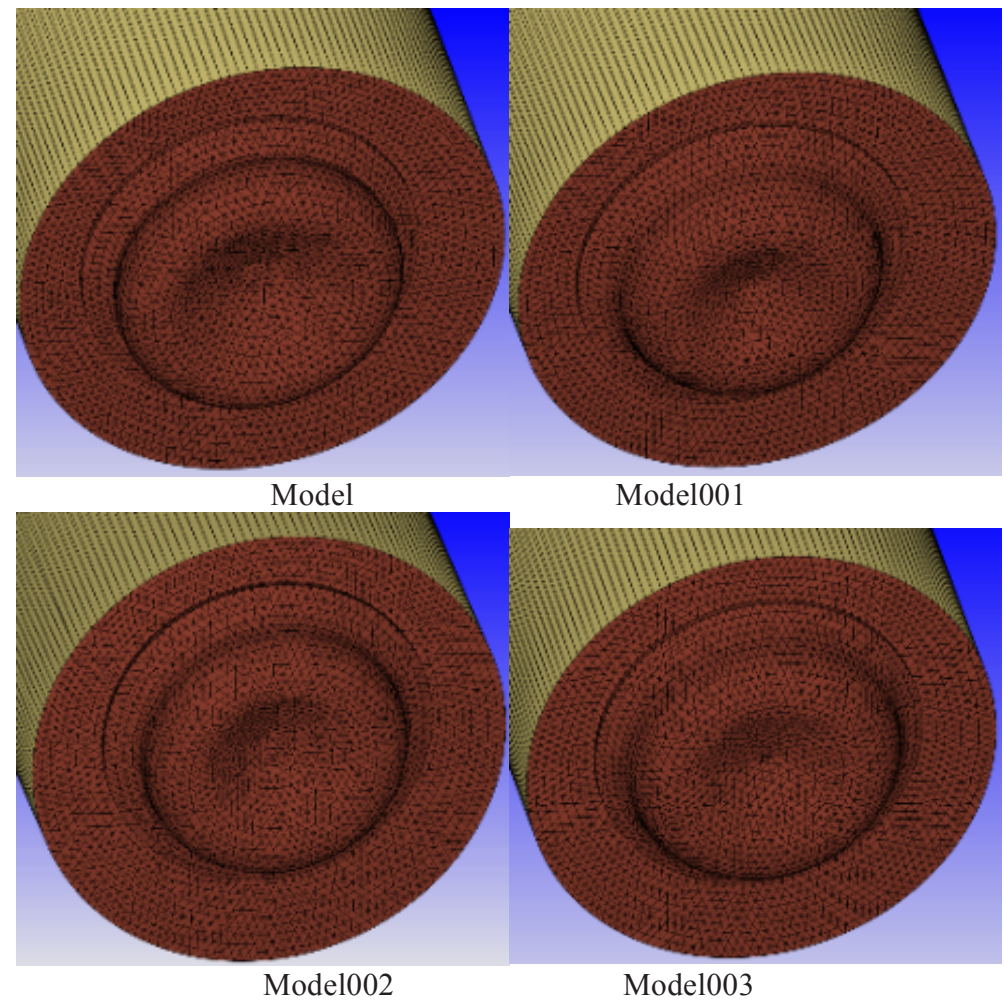

Fig. 3. 3D diagram of combustor scheme.

Table 5. Fuel injection strategy table.

\begin{tabular}{|c|c|c|c|c|c|c|}
\hline Plan & Parameter & Pre-spraying & $\begin{array}{c}\text { Interv } \\
\text { al }\end{array}$ & $\begin{array}{c}\text { Main } \\
\text { spraying }\end{array}$ & $\begin{array}{c}\text { Interv } \\
\text { al }\end{array}$ & $\begin{array}{c}\text { Post- } \\
\text { spraying }\end{array}$ \\
\hline \multirow{2}{*}{ A } & $\begin{array}{c}\text { Fuel injection } \\
\text { quantity/mg }\end{array}$ & 2 & - & 68.7 & - & 一 \\
\hline & $\begin{array}{c}\text { Crank Angle } /\left({ }^{\circ}\right. \\
\text { ATDC })\end{array}$ & $\begin{array}{c}-24.9 \text { to }- \\
21.6\end{array}$ & 14 & -7.6 to -5.1 & - & - \\
\hline \multirow{2}{*}{ B } & $\begin{array}{c}\text { Fuel injection } \\
\text { quantity/mg }\end{array}$ & 2 & - & 56.5 & - & 12.2 \\
\hline & $\begin{array}{c}\text { Crank Angle } /\left(^{\circ}\right. \\
\text { ATDC })\end{array}$ & $\begin{array}{c}-24.9 \text { to }- \\
21.6\end{array}$ & 14 & -7.6 to 2.84 & 10 & $\begin{array}{c}12.84 \text { to } \\
15.1\end{array}$ \\
\hline \multirow{2}{*}{$\mathrm{C}$} & $\begin{array}{c}\text { Fuel injection } \\
\text { quantity/mg }\end{array}$ & 2 & - & 49.49 & - & 19.21 \\
\hline & $\begin{array}{c}\text { Crank Angle } /\left(^{\circ}\right. \\
\text { ATDC })\end{array}$ & $\begin{array}{c}-24.9 \text { to }- \\
21.6\end{array}$ & 14 & -7.6 to 1.55 & 10 & $\begin{array}{c}11.55 \text { to } \\
15.1\end{array}$ \\
\hline
\end{tabular}

\section{Analysis of simulation results}

\subsection{Analysis of results of different injection strategies for the same geometric model}

$\mathrm{NO}_{\mathrm{X}}$ and soot quality change curves in cylinder under different injection strategies of the same combustion chamber with different geometric shapes are shown in Figure 4 and Figure 
5, and 3D turbulence distribution of combustion chamber model scheme is shown in Figure 6.

By comparing and analyzing Figure 4 and Figure 5, it can be seen that under the same combustion chamber geometric model, $\mathrm{NO}_{\mathrm{X}}$ and soot emission of injection Plan $\mathrm{A}, \mathrm{B}$ and $\mathrm{C}$ decrease accordingly.

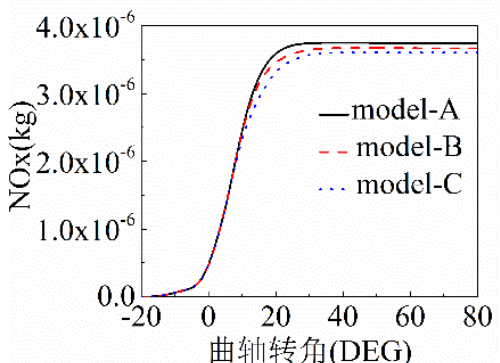

Model

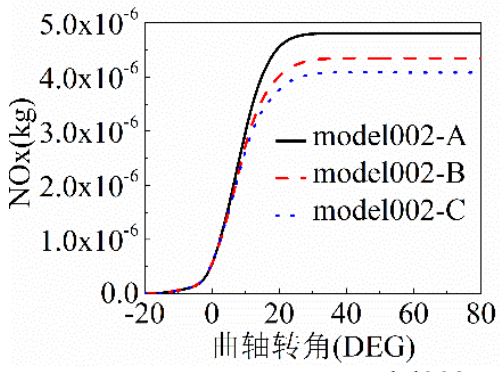

Model002
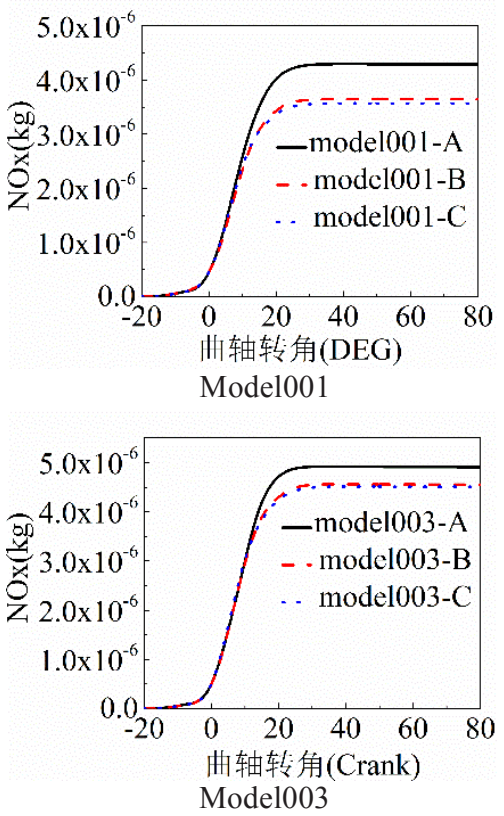

Fig. 4. NOx emissions from the same combustion chamber with different injection strategies.

Therefore, it can increase $\mathrm{NO}_{\mathrm{X}}$ and soot emission amount of Plan $\mathrm{B}$ and $\mathrm{C}$ during postspraying, and also decrease obviously compared with plan A without post-spraying. It is concluded that repeated injection can improve the mixing condition of oil and gas, so soot can be generated in several areas in the combustion chamber, and its distribution area is more widely. Therefore, soot is easier to be oxidized

In addition, soot generated during the later combustion period during single injection is difficult to be oxidized due to reasons such as approaching the end of combustion, insufficient oxidation time and rapid decrease of temperature in the power stage, while repeated injection can improve this state.

Meanwhile, it can be seen from Figure 4 and 5 that $\mathrm{NO}_{\mathrm{X}}$ and soot emission peak in cylinder of Plan C, with large amount of post-injection, is the smallest among the three injection strategies. Figure 6 shows that in Plan C, the turbulent kinetic energy in the cylinder is larger, and the equivalent ratio distribution in the cylinder is more uniform, which makes fuel combustion more sufficient.

On the other hand, the fuel injected after injection has large quality, so there is more fuel in the high-temperature region formed by early combustion, which can increase soot oxidation amount effectively, and thus reduce the generation of pollutants. 

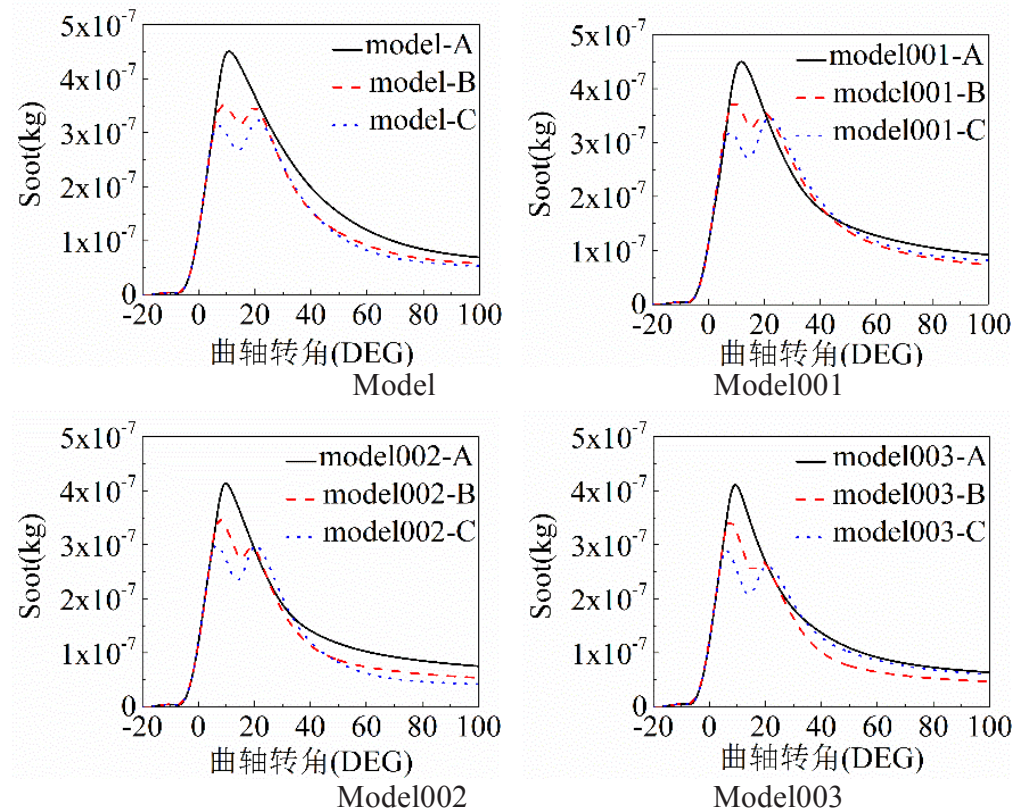

Fig. 5. Soot emission amount of the same combustion chamber with different injection strategy scheme.

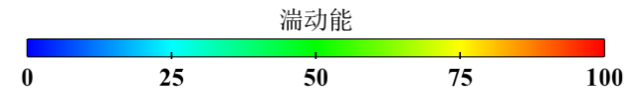

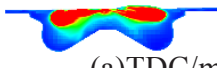

(a)TDC/model A

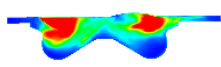

(d) $10^{\circ} \mathrm{ATDC} /$ model A

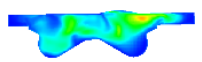

(g) $20^{\circ}$ ATDC/ model A

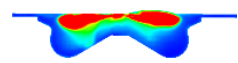

(b) TDC/model B

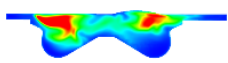

(e) $10^{\circ} \mathrm{ATDC} /$ model B

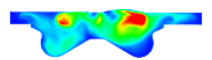

(h) $20^{\circ} \mathrm{ATDC} /$

model B

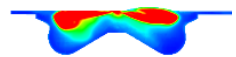

(c)TDC/model C

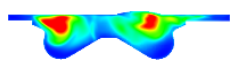

(f) $10^{\circ} \mathrm{ATDC} /$ model C

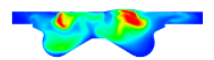

(i) $20^{\circ} \mathrm{ATDC} /$ model C

Fig. 6. Cloud atlas of turbulent kinetic energy distribution in different fuel injection strategies in combustor model schemes.

\subsection{Analysis of results of different geometric models under the same fuel injection strategy}

Under the same fuel injection strategy, the pressure and temperature curves of different combustor geometric model schemes are shown in Figure 7 and Figure 8 respectively.

By comparing and analyzing the results in Figure 7 and Figure 8, it can be found that under the same fuel injection strategy, the cylinder pressure and temperature in the combustion chamber geometric model model002 and model003 scheme are the highest. 
The analysis shows that the instantaneous heat release of mode1002 and model003 near the top dead center is large and lasting for a long time, while the cylinder content product is small at this time.

Therefore, its pressure and temperature rise rate is large, making its peak pressure and temperature higher.

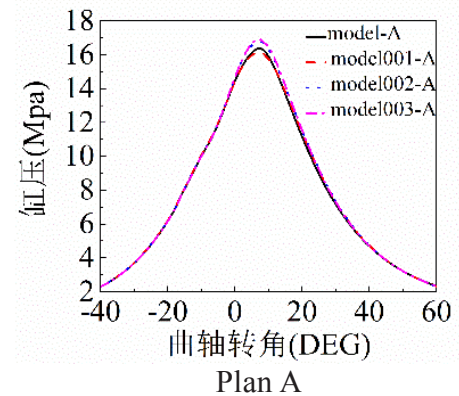

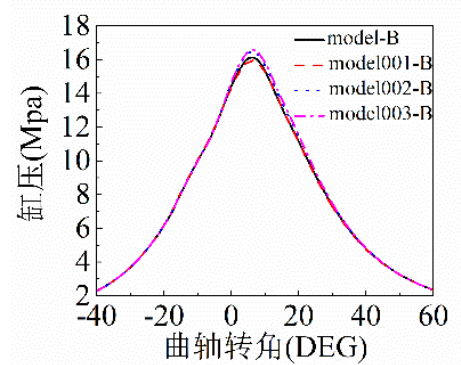

Plan B

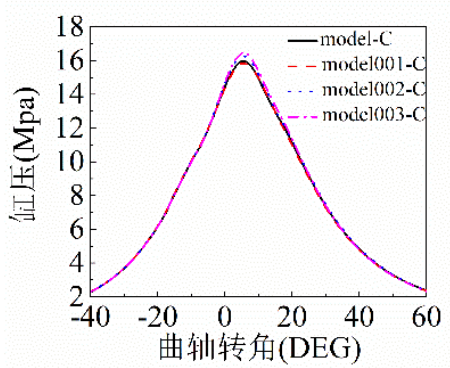

Plan C

Fig. 7. Cylinder pressure curves of different combustor schemes for the same injection strategy.

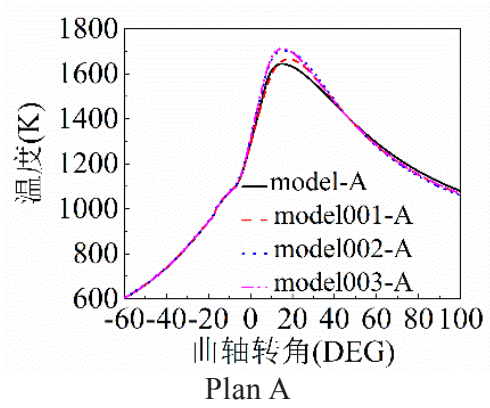

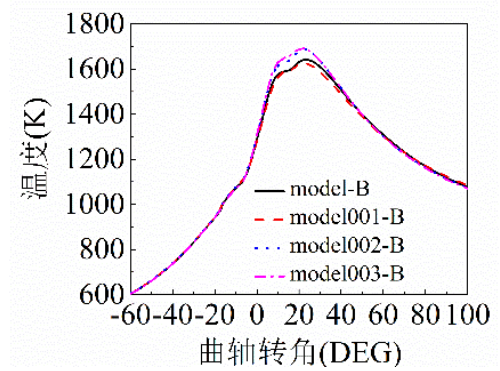

Plan B

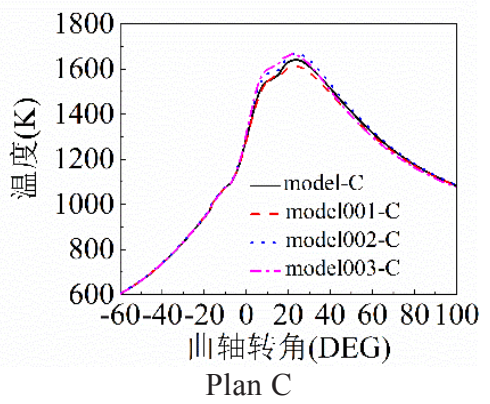

Plan C

Fig. 8. Different combustor temperature curves for the same injection strategy. 
Soot emission from different combustion chamber schemes with the same fuel injection strategy is shown in Figure 9. The equivalent ratio distribution and turbulence intensity distribution in the combustion chamber scheme of model, model 002 and model 003 are shown in Figure 10 and 11.

Comparing with Figure 9, it can be found that soot emission of combustion chamber geometric model model002 and model003 decreased under the same fuel injection strategy.

Therefore, through comprehensive analysis of two dimensional results, equivalent ratio distribution in Figure 10 and turbulence intensity distribution in Figure 11, it is found that scheme model002 and model003 have fewer regions with high equivalent ratio than the model scheme. Therefore, the distribution of oil and gas is more even, so it can burn more completely, and soot generation is less, and more evenly mixed with oil and gas makes soot generation area more, and thus increase its oxidation amount.

Meanwhile, it is found that model 002 and model 003 proposal has higher turbulence intensity than model proposal, and the higher turbulence intensity is beneficial to fuel air mixing and combustion, making soot emission less.
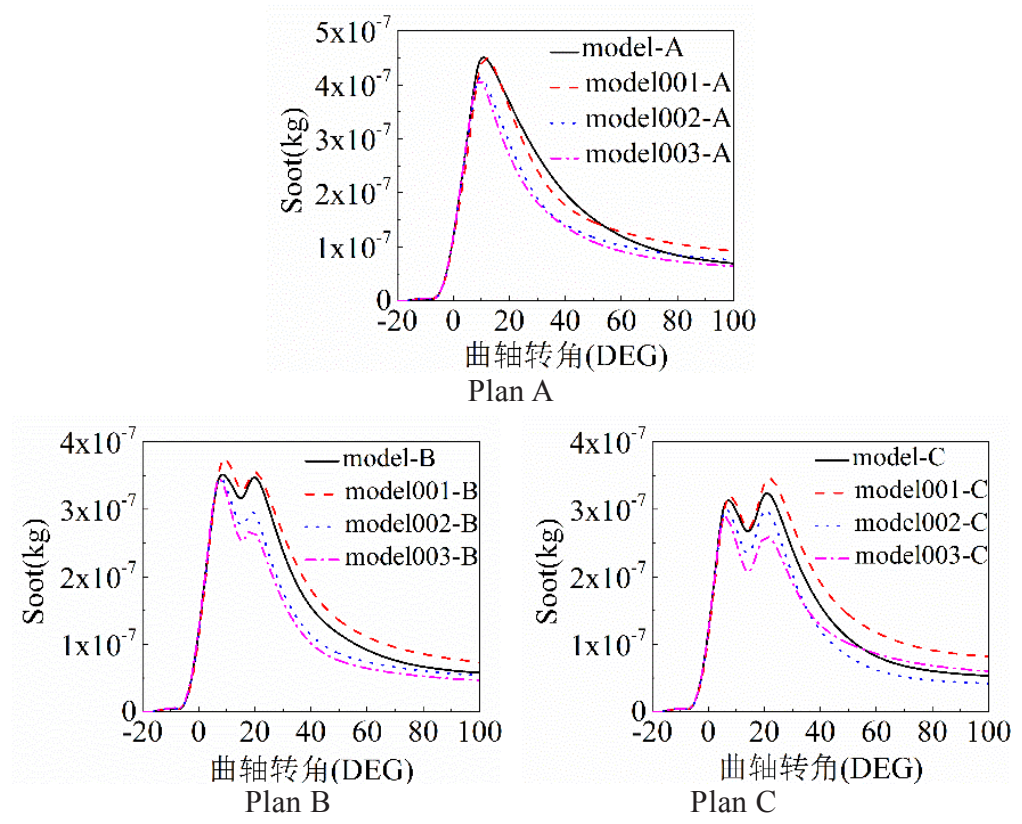

Fig. 9. Soot emissions from different combustion chamber schemes with the same fuel injection strategy.

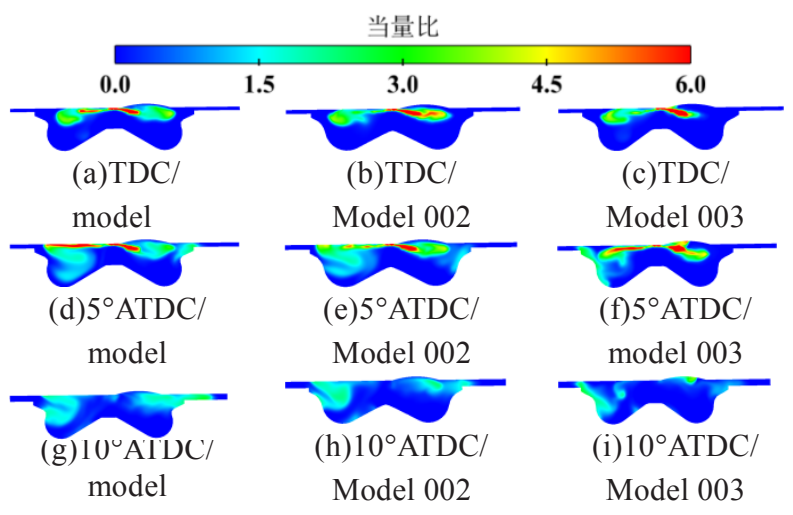


Fig. 10. Equivalent ratio distribution cloud graphs of different combustor under scheme $A$ of fuel injection strategy.

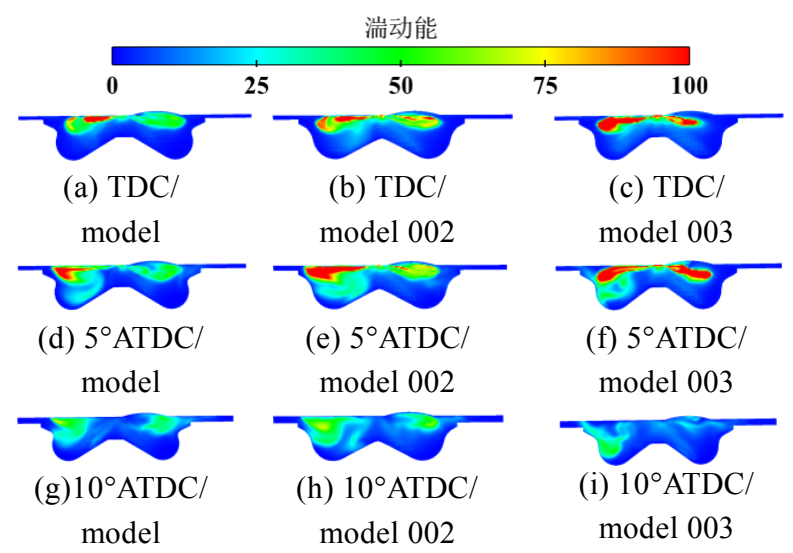

Fig. 11. Cloud graphs of turbulent kinetic energy distribution in different combustion Chambers under injection strategy A.

\section{Conclusion}

In this paper, the comprehensive influence of crater shape and fuel injection strategy on mixture, combustion and emission of diesel engine is studied in detail by numerical simulation under full load.

Main conclusions are as follow:

First of all, soot emission can be decreased significantly by repeated injection. Under the same combustion chamber shape, increase plan B and Plan C of the post-injection strategy can promote evenly mixing of oil and gas in the cylinder, making it less successful, and soot injection combustion in the early stage makes the temperature inside the cylinder higher, so it increases soot oxidation amount.

$\mathrm{NO}_{\mathrm{X}}$ and soot emission of three times injection plan $\mathrm{C}$ are the least.

Second, under the same fuel injection strategy, the instantaneous heat release of the combustor geometric model002 and model003 schemes near the top stop point is larger, and the cylinder pressure and the temperature inside the cylinder is higher.

Meanwhile, the reasonable combustion chamber geometry of these two schemes improves turbulent kinetic energy in the cylinder, which makes oil and gas mixing and distribution more even, and fuel evaporation and atomization more quickly, and thus makes combustion more sufficient, which reduces $\mathrm{NO}_{\mathrm{X}}$ and soot emission.

Project support: Zhejiang Province Key R\&D Project (2018C03037)

\section{References}

1. T. Husberg, I. Denbratt, A. Karlsson. Analysis of Advanced Multiple Injection Strategies in a Heavy-Duty Diesel Engine Using Optical Measurements and CFDSimulations. SAE paper, 2008, 2008-01-1328.

2. R. Mobasheri, Z. Peng, S.M. Mirsalim. Analysis the effect of advanced injection strategies on engine performance and pollutant emissions in a heavy duty DI-diesel 
engine by CFD modeling. International Journal of Heat and Fluid Flow, 2012, 33 (2012) 59-69.

3. T.N. Puri lng, L.R. Soni lng, S. Deshpande. Combined Effects of Injection Timing and Fuel Injection Pressure on Performance, Combustion and Emission Characteristics of a Direct Injection Diesel Engine Numerically Using CONVERGE CFD Tool. SAE paper, 2017, 2017-28-1953.

4. Zhang Yanhui, Du Hui, Sun Chuanhong. Research on optimization of a diesel engine combustion chamber based on numerical simulation[J].Internal Combustion Engine Engineering, 2018, 39(02):87-92.

5. R. Dakhore, N.G. Gandhi, N. Gokhale, et al. Effect of Piston Cavity Geometry on Combustion, Emission and Performance of a Medium Duty DI Diesel Engine. SAE paper, 2015, 2015-26-0198.

6. X. Li, Y. Chen, L. Su, F. Liu. Effects of lateral swirl combustion chamber geometries on the combustion and emission characteristics of DI diesel engines and a matching method for the combustion chamber geometry. Fuel, 2018, 224 (2018) 644660.

7. BEALE J C, REITZ R D. Modeling spray atomization with the KelvinHelmholtz/Rayleigh-Taylor hybrid model[M]. Atomization and Sprays, 1999,9(6):623650 .

8. Gu Yumeng, Li Tie,Wei Yijie,et al. Numerical experimental study of KH-RT model in diesel spray evaporation simulation[J].Internal Combustion Engine Engineering, 2019, 40(01): 36-41+49.

9. RA Y, REITZ R D. A vaporization model for discrete multi-component fuel sprays[J]. International Journal of Multiphase Flow,2009,35(2):101-117.

10. WANG H, REITZ R D, YAO M F, et al. Development of an n-heptane-n-butanolPAH mechanism and its application for combustion and soot prediction[J]. Combustion and Flame,2013,160(3):504-519. 